\title{
EDUCAÇÃO PARA PAZ NO CURSO PRÉ UNVERSITÁRIO POPULAR CULTURA DA PAZ EM RIO GRANDE-RS
}

\author{
EDUCACIÓN PARA LA PAZ EN CURSO PRE UNIVERSIDAD \\ CULTURA POPULAR DE LA PAZ EN RÍO GRANDE-RS \\ EDUCATION FOR PEACE IN THE COURSE PRE-UNIVERSITY \\ POPULAR CULTURE OF PEACE IN RIO GRANDE-RS
}

\author{
Jéssica Rocha Senna ${ }^{1}$ \\ Peterson Fernando Kepps da Silva ${ }^{2}$ \\ Vilmar Alves Pereira ${ }^{3}$
}

\begin{abstract}
Resumo
Este trabalho apresenta um relato de experiência a partir do projeto intitulado "Cultura da Paz", no qual busca possibilidades tanto de reflexão acerca da vida quanto do ingresso de sujeitos privados de liberdade ao Ensino Superior. O curso pré-universitário "Cultura da Paz" é um projeto de extensão desenvolvido pela Universidade Federal do Rio Grande (FURG), a partir do Programa de Auxílio ao Ingresso nos Ensinos Técnico e Superior (PAIETS). Os estudantes que integram o curso são, exclusivamente, apenados do regime aberto e semiaberto da Penitenciária Estadual do Rio Grande (PERG). Tendo por referência os conceitos de Educação Para Paz e Justiça Restaurativa objetivamos, apresentar algumas ações desenvolvidas ao longo dos seus dois anos de vigência, e também a fecundidade dessas duas categorias para pensarmos novos paradigmas de justiça social e de direitos humanos. A experiência ocorreu nos extremos sul do Brasil em Rio Grande-RS.
\end{abstract}

Palavras-Chave: Cultura da Paz; justiça restaurativa; pré-universitário popular; educação popular.

\section{Resumen}

Este trabajo presenta un relato de experiencia a partir del proyecto titulado "Cultura de la Paz", en el que busca posibilidades tanto de reflexión acerca de la vida como del ingreso de sujetos privados de libertad a la Enseñanza Superior. El curso preuniversitario "Cultura de la Paz" es un proyecto de extensión desarrollado por la Universidad Federal de Rio Grande (FURG), a partir del Programa de Auxilio al Ingreso en las Enseñanzas Técnico y Superior (PAIETS). Los estudiantes que integran el curso son, exclusivamente, apenados del régimen abierto y semiabierto de la Penitenciaría Estadual del Río Grande (PERG). Con respecto a los conceptos de educación para la paz y la justicia restaurativa, presentamos algunas acciones desarrolladas a lo largo de sus dos años de vigencia, y también la fecundidad de esas dos categorías para pensar nuevos paradigmas de justicia social y de derechos humanos. La experiencia ocurrió en los extremos sur de Brasil en Rio Grande-RS.

Palabras claves: Cultura de la Paz; justicia restaurativa; pré-universitario popular; educación popular.

\footnotetext{
${ }^{1}$ Graduada em Ciências Biológicas - Licenciatura pela Universidade Federal do Rio Grande. Coordenadora do Pré-Universitário Cultura da Paz.

${ }^{2}$ Professor de Ciências e Biologia licenciado pela Universidade Federal do Rio Grande. Mestre em Educação em Ciências Química da Vida e Saúde. Coordenador Adjunto do Pré-Universitário Cultura da Paz.

${ }^{3}$ Coordenador do Programa de Auxílio aos Ensinos Técnico e Superior da Universidade Federal do Rio GrandePAIETS-FURG. Bolsista de Produtividade do CNPq- Nível 2.
} 


\begin{abstract}
This work presents an experience report from the project entitled "Culture of Peace", in which it looks for possibilities both for reflection on the life and the entrance of subjects deprived of freedom to Higher Education. The pre-university course "Culture of Peace" is an extension project developed by the Federal University of Rio Grande (FURG), based on the Technical and Higher Education Entrance Aid Program (PAIETS). The students that integrate the course are, exclusively, distressed from the open and semi-open regime of the State Penitentiary of Rio Grande (PERG). With reference to the concepts of Education for Peace and Restorative Justice we aim to present some actions developed during its two years of validity and also the fecundity of these two categories to think about new paradigms of social justice and human rights. The experiment took place in the southernmost regions of Brazil in Rio Grande-RS.
\end{abstract}

Keywords: Culture of Peace; restorative justice; popular pre-university; popular education.

\title{
1. Introdução
}

Dentre as inúmeras patologias que assolam as sociedades contemporâneas a cultura da violência cotidianamente amplia seus vestígios com diferentes faces, nomes, contextos, raças, sistemas e credos. Esses sintomas demonstram os sinais de uma sociedade que adoeceu principalmente no campo das questões humanas. Desse modo emancipação e a garantia de direitos almejados no horizonte iluminista esperançoso são postos em suspeita. De certa maneira vivemos algo paradoxal: somos e atingimos muitas vitórias em questões de tecnologias mas temos muitas dificuldades de avançar no terreno do cuidado com as relações entre humanos e também com os não humanos.

Uma leitura mais pragmática e pessimista olhando para as estatísticas de números de humanos que sofrem violências cotidianas coloca os processos modernos de racionalidade e de subjetividade num campo de fragilidade e denuncia como pseudas as emancipações que foram extremamente defendidas. Afinal o que estaria ocorrendo os humanos que não conseguiram criar formas de convivência humanizadoras, com dignidade e paz?

Estando na fronteira epistêmica entre o desencanto e a utopia, há aqueles como nós que não permitimos que a patologia da desesperança nos encerre num pessimismo antropológico limitando nossa vocação ontológica de ser mais como tanto almejou e defendeu Paulo Freire. Desse modo, vivendo nesse momento num Brasil de extremos e convivendo com sentimentos antagônicos que estão na raiz dos novos fundamentalismos e radicalismos brasileiros (ódio, vingança e fobia), nos permitimos nos mobilizar no sentido de buscarmos alguns rasgos na perspectiva da Educação Para a Paz e da Justiça Restaurativa, apresentando uma singela experiência com pessoas com liberdade privada no contexto de um curso pré-universitário popular em Rio Grande- RS.

O objetivo maior consiste ao apresentar as experiências acenar para outras possibilidades que não a desse paradigma esgotado da violência pela violência e da justiça pela punição. 


\section{Primeiros movimentos}

No ano de 2016 emerge um projeto social cujo objetivo é possibilitar a apenados da penitenciária Estadual do Rio Grande (PERG) o ingresso a uma universidade. Explicamos melhor. Em conjunto com a Universidade Federal do Rio Grande (FURG) e o Programa de Auxílio aos Ensinos Técnico e Superior (PAIETS), projeto no qual visa a inserção, por meio de cursos populares pré-universitários gratuitos, de estudantes ao Ensino Superior, foi desenvolvido o curso popular denominado "Cultura da Paz".

Em março do referido ano, decidimos apresentar o projeto do curso para o grupo de coordenação da Penitência Estadual de Rio Grande - PERG. Após contato prévio via telefone com o diretor da penitenciária, agendamos um dia para exposição da proposta. Chegando lá, fomos recebidos pelo diretor da instituição, assistentes sociais e psicólogas. Detalhamos o objetivo do curso, metodologia de trabalho e discutimos algumas questões legais, tais como: documento de liberação dos educandos pelo juiz; ata de presença com dia, hora de entrada e saída e assinatura do estudante e do professor responsável; e aviso diário à coordenação da PERG via telefone sobre a ata de presença.

Depois de muita conversa, deixamos acordado que criaríamos um termo de compromisso, no qual estabelecia o tempo de duração do curso, horário das aulas e local das mesmas, sendo proibida ainda a divulgação de fotos dos educandos e o uso de celulares no período de aula, assim como qualquer mudança e/ou alteração/problema seria comunicada as coordenações, relatando a situação a fim de buscar soluções. Assinaram o termo a direção da PERG e representantes da Universidade. Além disso, a assistente social ficou encarregada de fazer um levantamento de quantos apenados gostariam de participar do curso, bem como manter contato com a coordenação do curso popular "Cultura da Paz". Sobre o levantamento, inicialmente tivemos um alto número de apenados interessados em participar, entretanto, a vinculação de muitos foi inviabilizada por não corresponder critérios como de comportamento no presídio estabelecidos pela PERG.

Como pode ser percebido, o curso se fez a partir de muitas mãos, de pessoas interessadas e comprometidas com a educação e com a inserção destes sujeitos no meio social. As parcerias foram vitais para o curso. A título de exemplo, tanto os professores de todas as disciplinas quanto a coordenação eram voluntários. Ainda cabe destacar que o curso se configurou como um pré-universitário popular, voltado aos detentos do regime aberto e semiaberto da PERG. No regime semiaberto, os apenados são liberados para trabalhar e/ou estudar, mas permanecem na penitenciária para dormir e aos finais de semana e feriados; já o 
regime aberto, a execução da pena se dá em liberdade. Neste sentido, os estudantes do curso "Cultura da Paz" tinham a possibilidade de reduzir um dia de pena a cada três dias estudados.

Sobre a proposta curricular, destacamos que as aulas englobavam o conteúdo das disciplinas expostas de maneira expositiva-dialógica, de forma que os educandos se tornassem sujeitos de seu processo de aprendizagem. As disciplinas ministradas pelos educadores voluntários estão em concordância com as áreas de conhecimento cobradas no ENEM (Exame Nacional do Ensino Médio), a saber: Linguagens e Códigos; Ciências Humanas; Ciências da Natureza; e Matemática. Além disso, as aulas eram desenvolvidas no turno da noite no campus da FURG. Porém, não somente aulas teóricas fazem o substrato de formação do curso popular "Cultura da Paz", uma série de outras propostas, atividades e participação em eventos fizeram parte do nosso cotidiano.

Com o pensamento voltado para o tipo de estudantes participante deste projeto, a metodologia visou sempre à viabilização da aprendizagem de modo a construir os conhecimentos levando em consideração, também, as experiências, vivências e contextos dos educandos. Por isso, não voltamos nossos esforços para aplicação ou replicação de conteúdos, embora um curso pré-universitário possa sugerir essa ideia. Buscamos, justamente, propiciar que o espaço de sala de aula se tornasse fonte de expressão de todos os tipos de saberes e realidades. Consideramos a heterogeneidade desse público, seus interesses, suas identidades, suas preocupações, necessidades, expectativas em relação à escola/curso, suas habilidades, enfim, suas vivências se tornam de suma importância para a construção da proposta pedagógica.

Pensando ainda nessa proposta curricular dialógica e intersecionada com as realidades dos educandos, construímos oficinas pedagógicas; participamos de exposições interativas; desenvolvemos propostas em parceria com psicólogos; e oficinas pedagógicas. Com relação as oficinas pedagógicas (ou oficinas de ensinos), Vieira e Volquind (2002) nos diz que elas podem ser entendidas como uma proposta que cria condições para a vivência do estudante, a promoção da reflexão e a construção de conhecimentos; não somente um espaço ou uma prática cuja função é aprender fazendo. Os autores consideram que aspectos como "o pensar, o sentir, o intercâmbio de ideias, a problematização, o jogo, a investigação, a descoberta e acooperação" (p. 12) são elementos que compõem as propostas das oficinas.

Nesta perspectiva, o trabalho das oficinas desenvolvidas no curso popular "Cultura da Paz" buscou se utilizar destes aspectos para desenvolver propostas que tramem os interesses dos estudantes e propicie a troca e a construção de conhecimentos de forma mais dinamizada. Outro ponto a ser colocado, é a forma colaborativa com que acontecem as oficinas. Para 
serem construídas, elas passam por etapas como: 1) emergem das inquietações dos estudantes; isto é, por meio das dúvidas, questionamentos e perguntas sobre determinado tema; 2) a partir do tema de interesse dos estudantes, há o contato com profissionais da área referente; ou seja, se as indagações perpassam o campo da saúde, indivíduos desta área serão convidados a desenvolverem uma oficina; 3) as inquietações dos estudantes são repassadas ao profissional da área. A mediação entre professor, coordenação e profissional da área específica é de extrema importância, tendo em vista que as oficinas são desenvolvidas a fim de contemplar as proposições dos estudantes.

Não podemos deixar de tratar ainda, mesmo que brevemente, o contexto prisional brasileiro. As superlotações dos presídios, a atuação de facções criminosas e a precarização do espaço físico são conhecidas por todos nós e, também, são oficializados em dados divulgados pelo Departamento Penitenciário Nacional (DEPEN, 2014). Segundo o DEPEN (2014), o Brasil se encontra na quarta colocação no que se refere aos países do mundo com maior população prisional. Ainda em escola mundial, estamos entre os países que possuem maior número de presos provisórios - pessoas que foram presas e aguardam julgamento. Já a escolarização das pessoas presas no Brasil, perpassa, basicamente, pelo Ensino Fundamental incompleto (BRASIL, 2012).

Em meio a este cenário, em que sujeitos muitas vezes vivenciam uma realidade com menos oportunidades de emprego, com menos acesso a elementos básicos, como alimentação e saneamento básico, e maior vulnerabilidade social, buscamos situar o curso popular "Cultura da Paz". Não com a prerrogativa ou ideia que vamos "salvar" os detentos e "livrálos" de toda uma série de preconceitos e inacessibilidade a questões básicas para sobrevivência, mas como um espaço que pode extrapolar fronteiras e mostrar outras formas de sermos e vivermos. Buscamos viabilizar isso por meio da educação, de propostas pedagógicas, do diálogo e da discussão. Não se trata aqui de vitimizar estes sujeitos, objetivamos com todo este trabalho, contribuir com suas formações e apresentarmos a educação como ferramenta ou instrumento de transformação, tanto social quanto pessoal.

Na próxima seção, vamos discutir sobre a relevância da justiça restaurativa no contexto do pré-universitário "Cultura da Paz"; já na seção 4 apresentaremos de forma mais detalhada as oficinas que mencionamos anteriormente, bem como algumas ações que desenvolvemos ao longo dos dois anos de vigência do curso.

\section{Justiça restaurativa}

A justiça restaurativa se mostra como um modelo mais humano, que aproxima as partes, realmente envolvidas e afetadas pelo delito e devolve a estas a competência de resolução dos 
conflitos. Brancher afirma que "a Justiça Restaurativa serve para definir uma nova abordagem para as questões dos crimes e das transgressões que ela possibilita um referencial paradigmático na humanização e pacificação das relações sociais envolvidas num conflito". Segundo ele, Como a questão da violência e da criminalidade está, em regra, associada a relações conflitivas que evoluem de forma descontrolada, as denominadas práticas restaurativas - soluções de composição informal de conflitos inspiradas nos princípios da Justiça Restaurativa - tem passado a representar uma poderosa ferramenta de implementação da cultura de paz em termos concretos.

Para a vítima, como protagonista principal, a Justiça Restaurativa surge para levar a sério suas necessidades. Conforme Zehr (2012), os ofensores precisam que a Justiça lhes ofereça responsabilização que cuide dos danos resultantes, estimule a empatia e a responsabilidade e transforme a vergonha, assim como estímulos para a transformação pessoal, incluindo a cura dos males que contribuíram para o comportamento lesivo, oportunidades de tratamento para dependências químicas e/ou outros problemas e aprimoramento de competências pessoais, além de estímulo e apoio para reintegração à comunidade e, em alguns casos, detenção, ao menos temporária.

$\mathrm{Ou}$ seja, segundo os autores supracitados, a Justiça Restaurativa não pode ser entendida como uma forma de justiça alternativa, mas uma maneira de solução paralela, que precisa conviver com a justiça tradicional, visto ser aplicável em circunstâncias peculiares, pois depende fundamentalmente da admissão pelo transgressor quanto à verdade dos fatos, bem como da concordância de todos os interessados na solução do problema. Também não se confunde com as correntes jurídicas do abolicionismo penal, visto que não prega a impunidade. Ao contrário, combina elementos aparentemente contraditórios como assistência e controle, ou afeto e limites, de forma a assegurar maior intensidade na resposta pública à questão do crime e das transgressões.

Para a vítima, um ato criminoso sempre gera medo, impotência e revolta. O autor do crime será colocado em frente a vítima dependendo da capacidade de superação da mesma e assim, como todas as partes precisam ser ouvidas, esse processo de conciliação é promovido por meio de debates em mesas-redondas ou em círculos. $\mathrm{O}$ agressor é convidado a assumir a responsabilidade pelas consequências do seu comportamento e pelos prejuízos (materiais e morais) sofridos pela vítima. Reconhecendo as consequências e o dano da vitimação estimula a vítima a tornar-se parceiro no processo de comunicação orientado para a reparação e a indenização. 
Já a cultura da paz pode ser definida como: "conjunto de valores, atitudes, comportamentos e modos de vida que rejeitam a violência e previnem os conflitos, atacando suas causas para resolver os problemas através do diálogo e negociação entre indivíduos, grupos e nações" (ONU, 2014). Portanto, ela é um modelo de conciliação entre vítimas e agressores em casos de crimes de pouco poder ofensivo atendendo a alguns limites quanto à pena. Esse modelo restaurador é uma proposta humanizadora, que busca a redução da violência, tratando o agressor com dignidade para evitar a punição coercitiva do sistema penal atual, buscando a reintegração do apenado de forma digna na comunidade depois de ter sido responsabilizado por suas más ações. Assim, a comunidade tem a garantia que medidas são tomadas diante de um ato criminoso e os transgressores serão reintegrados às suas comunidades.

No desenvolvimento das atividades tivemos por orientação algumas recomendações que ao nosso entender orientaram a perspectiva dessa experiência:

1. Promover uma educação que envolva valores humanos e sociais, resolução de conflitos através do diálogo e a construção da justiça (Nascimento, 2000).

2. Desenvolver uma cultura dos direitos humanos através do reconhecimento da dignidade de cada pessoa (Candau,2005).

3. Redefinir o papel da educação, onde predomine a forma da "violência estrutural" (Nascimento, 2000).

4. Dar voz aos estudantes e desenvolver formas participativas de construção de normas (Nascimento, 2000).

5. Lutar pela manutenção da paz ressaltando a valorização da ética, da criatividade, das experiências e da reflexão constante sobre nossas ações (Beauclair, 2007).

6. Identificar recursos e material de apoio a serem utilizados num curso, currículo ou programa em EPP, quer seja ele informal ou formal (Morrison \& Harris, 2003).

7. Refletir sobre o impacto de nossas ações sobre o meio físico e psicológico da escola e do ambiente à nossa volta (Beauclair, 2007).

8. Estimular a aquisição de competências, as quais os alunos poderão utilizar para desenvolverem estratégias não-violentas para toda a vida (Columa, 2001).

9. Focar na formação de um ser social com o potencial de falar e se comunicar, como principal estratégia para a resolução de conflitos (Nascimento, 2000).

10. Criar sentido para a construção de um novo tempo num mundo em complexa interdependência (Beauclair, 2007). (COLUMA, 2007, p.-3).

Esses elementos contribuíram significativamente para que pudéssemos desenvolver uma educação não violenta em defesa da vida. 


\section{Os dois anos de vigência do curso Pré-universitário Popular "Cultura da Paz"}

O curso, como já pode ser percebido, teve dois anos de vigência, 2016 e 2017. No ano de 2018 tivemos que interromper nosso trabalho devido a um incêndio no albergue, local onde ficam os apenados do regime semiaberto - público participante do projeto. Mas, antes disso, tivemos um total de nove alunos no primeiro ano e três alunos no segundo. O número de educadores voluntários foi de treze, já o de coordenadores, quatro. Torna-se importante encarar estes números de modo a percebê-los como sujeitos, um grupo de professores, coordenadores, estudantes, enfim, pessoas que se propuseram a buscar, por meio do processo educativo, diminuir desigualdades e ampliar oportunidades.

Com relação a esse processo educativo, desenvolvemos simulados, rodas de conversa, aulas de músicas, palestras e parcerias com projetos da FURG, como a "Feira de Profissões", realizada nos espaços da universidade. Sobre esta feira, de forma sintética, a universidade abre o Campus para aos alunos dos pré-universitários populares, para que eles possam conhecer um pouco da instituição, como suporte que a universidade recebe e direitos dos estudantes no contexto universitário e também com uma visita monitorada pelos campus como, prédios, laboratórios e salas "especializadas" de acordo com a área desejada de cada educando.

Em outra ação, contamos com a parceria de psicólogos do Centro Regional de Estudos, Prevenção e Recuperação de Dependentes Químicos (CENPRE), também vinculado à FURG. No decorrer das aulas, sentimos a necessidade de estabelecer uma parceria com o CENPRE, para possibilitarmos a reflexão dos nossos estudantes com assuntos como o uso de drogas e os seus efeitos ao organismo humano. Devido recorrência de relatos e duvidas que permeavam os alunos, no primeiro encontro realizamos uma oficina que contou com a participação de todos os estudantes, alguns professores do projeto "Cultura da Paz" e os integrantes do CENPRE. A proposta se iniciou com uma palestra, ministrada pelos psicólogos, sobre "Saúde mental, trabalho e projeto de vida" com a intenção de promover a reflexão e o senso crítico. Cada participante recebeu uma folha com perguntas sobre projetos e metas de vida, que deveriam ser respondidas individualmente e depois guardadas pelos próprios, com o objetivo de relerem, refletirem e não deixar que seus sonhos sejam "perdidos" durante as suas trajetórias.

A oficina não tinha o intuito expor o que cada um respondeu no seu questionário, porém, surgiu a vontade de um educando compartilhar sua escrita e todos resolveram levar suas respostas para uma conversa em grupo. A vontade de ingressar em uma universidade, de ter uma profissão ou até mesmo de ser um empreendedor se destacaram ao longo desta troca 
de experiências. Eles pontuaram que essa vontade surge devido a grande dificuldade de empregabilidade após o cumprimento da pena em um presídio. Em seguida, foi proposta uma roda de conversa, onde foi explicado o que é o CENPRE, quem e quando procurá-los e como é feito o trabalho de prevenção e reabilitação dos dependentes químicos.

Nossos educandos eram muito alegres e festivos. Depois de muitas batucadas nas mesas, conversamos com um instrutor de banda marcial que sugeriu uma oficina sobre música e ritmos. Esse instrutor e professor de música construiu uma proposta que se deu em roda, cada estudante tinha que repetir um som, por exemplo: o primeiro da roda fazia um som juntamente com um passo de dança, como duas batidas com o pé; o segundo reproduzia o som anterior e acrescentava mais um som, e assim por diante. Se não errassem, ao final, teríamos um som mais sincronizado e construído coletivamente.

Procurando satisfazer as expectativas dos estudantes sobre questões jurídicas, elaboramos uma oficina baseada nas indagações dos mesmos. Ao longo das aulas, percebemos que os alunos, frequentemente, voltavam-se a perguntas do campo do direito, principalmente sobre processos judiciais. Em nosso grupo não havia nenhum profissional apto a atender estas inquietações. Então, convidamos um profissional do direto, bacharel, que realizou, a nosso convite, mais uma oficina. Essa oficina foi desenvolvida com o intuito de complementar algumas destas dúvidas e propiciar um espaço de discussão com um viés mais "social" do direito.

A convidada é bacharel em direito e não advogada, porque não queríamos que a oficina virasse uma possível relação comercial. Já a elaboração da oficina teve como ponto de partida as inquietações dos estudantes; para isso, solicitamos que eles escrevessem em um papel anonimamente o que estavam interessados no que tange às questões de leis e sistema judicial para, então, encaminharmos estas dúvidas para a profissional. Foi a partir destas indagações relatadas pelos alunos que a oficina foi construída. As principais discussões entre os estudantes e a profissional convidada pairaram em torno do auxílio reclusão, o direito de apenados com relação à deficiência motora, bem como a saúde no sistema prisional e os portadores de HIV.

Questões de doenças e saúde são fortemente levantadas pelos estudantes, tanto por muitos possuírem doenças crônicas devido à exposição direta com outros indivíduos que, por vezes, são acometidos por doenças contagiosas e também por dividirem o mesmo espaço que estes sujeitos. As doenças como pneumonia, sífilis, leptospirose, HIV, hepatite e outras fazem parte das indagações dos estudantes, juntamente com o processo de tratamento e o atendimento básico em uma unidade de saúde. Considerando este contexto e o município do 
Rio Grande, cidade na qual eles residem, uma profissional da saúde, enfermeira, desenvolveu a oficina voltada para temáticas como doenças mais prevalentes na cidade, prevenção e tratamento do HIV e sífilis e testes rápidos disponíveis na rede básica de saúde.

Seguindo nosso breve contorno pelas as ações ocorridas no pré-universitário "Cultura da Paz", destacamos uma oficina sobre patrimônio (entendendo patrimônio como um conjunto de bens pertencente a uma pessoa). A oficina buscou discutir a teoria e produzir um material envolvendo estas questões. O trabalho se dividiu em duas partes; a primeira, com uma discussão reflexiva sobre o conceito e as aplicações de patrimônio material e imaterial. A segunda parte consistiu na interferência em fotografias impressas, por meio de agulha e linhas. Alguns materiais foram disponibilizados aos estudantes, assim como apresentados artistas que trabalham com a metodologia de costura de interferências, no intuito de os estudantes se apropriarem da técnica e vivenciarem de maneira mais próxima este tipo de intervenção artística.

Além disso, os educandos ao final de cada ano participavam do "Aulão", que é uma aula de fechamento, que ocorre às vésperas do ENEM. Esse "Aulão" tem o intuito de descontraí-los e estimulá-los para realizarem uma boa prova, diminuir a ansiedade e esclarecer possíveis dúvidas.

Ao longo desta seção podemos apresentar, mesmo que brevemente as oficinas realizadas com os educandos. Os professores do curso, pela mesma via, também desempenhavam ações, trabalhos e projetos em suas aulas de acordo com os conteúdos e assuntos que estavam discutindo. Um ponto importante de realçar é que nossas atividades sempre partiram das inquietações, dúvidas e anseios dos estudantes. Assim como as propostas se deram por meio de parcerias, com profissionais que se propuseram a realizá-las de modo a considerar as nossas necessidades e realidades. Tivemos um excelente retorno por parte dos estudantes. A participação ativa, o respeito, o diálogo, a troca de experiências foram mote, ou seja, alicerçaram todas as oficinas realizadas.

\section{Considerações finais}

Esta experiência demonstrou a fecundidade da Educação para paz aproximada de contexto da Educação Popular onde sujeitos "arranhados pela vida" puderam encontrar espaços de ressignificar suas existências a partir do horizonte da paz e da justiça restaurativa. A educação popular contribuiu no reforço e no reconhecimento de saberes desses sujeitos. Também serviu para reforçar o pertencimento, além de indicar possibilidades esperançosas 
sobre o porvir. A educação para paz permitiu o desenvolvimento da abordagem integral do ser humano em cada educando. Aquele espaço educativo para nós e para eles sempre foi visto como um espaço de cuidado integral e reconhecimento das múltiplas dimensões que constitui a nossa humanidade. O olhar da justiça restaurativa propiciou-nos um trabalho desmistificador. Ali não esses sujeitos não foram mais olhados pelos seus equívocos pretéritos, mas pelo seu vir-a-ser de possibilidades.

Por fim, concluímos que o curso popular Cultura da Paz cumpriu seu papel social, possibilitou, por meio da educação, a construção de novos olhares, assim como abre espaço para uma população marginalizada e, não raro, sem acesso a necessidades básicas no que tange a saúde, educação e moradia.

\section{Referências}

BRASIL, Portal Brasil. 2012. Levantamento mostra escolaridade dos presidiários no País. Disponível em: http://www.brasil.gov.br/educacao/2012/04/levantamentomostraescolaridade-dos-presidiarios-no-pais . Acesso em: 06 outubro 2017.

BRANCHER, Leoberto Narciso. Justiça restaurativa: a cultura de paz na prática da justiça. Disponível em < http://jij.tjrs.jus.br/justica-restaurativa/cultura-de-paz-na-pratica-dajustica> Acesso em: 17 março de 2016 às 10:06

COLUMA, Elizabeth dos Santos. Como educar para a paz. Psicol. Esc. Educ.

(Impr.)[online]. 2007, vol.11, n.2 [cited 2019-06-11], pp.431-433. Available from: $<$ http://www.scielo.br/scielo.php?script=sci_arttext\&pid=S1413$85572007000200023 \& \operatorname{lng}=$ en\&nrm=iso $>$. ISSN 2175-3539. http://dx.doi.org/10.1590/S1413-85572007000200023.

DEPEN, Departamento Penitenciário Nacional. 2014. Levantamento Nacional de Informações Penitenciárias. Disponível em: http://www.justica.gov.br/noticias/mjdivulgaranovo-relatorio-do-infopen-nesta-terca-feira/relatorio-depen-versao-web.pdf.. Acesso em: 06 outubro 2017.

ONU. Organização das Nações Unidas. Declaração e Programa de Ação sobre uma Cultura de Paz das Nações Unidas. Disponível em:

http://www.comitepaz.org.br/download/Declara\%C3\%A7\%C3\%A30\%20e\%20Programa\%2 0de\%20A\%C3\%A7\%C3\%A3o\%20sobre\%20uma\%20Cultura\%20de\%20Paz\%20\%20ONU.pdf. Acesso em: 02 maio 2014.

PEREIRA, Vilmar Alves; DIAS, J. R. L. ; TELMO . Educação Popular e a Pedagogia da Contra Marcha: uma homenagem a Gomercindo Ghiggi.. 1. ed. Passo Fundo: Méritos, 2013. v. 1. 246p. 
ROLAN, HAMMES, HAMMES. A resolução de conflitos e a educação para a paz.

Jaguarão, in: Revista Latino-Americana de Estudos em Cultura e V. 05, ed. especial, abr., 2019, artigo $\mathrm{n}^{\mathrm{o}} 1311$

VIEIRA, E. VOLQUIND, L. Oficinas de ensino: O quê? Por quê? Como? Porto Alegre: Edipucrs, 2002. 57p.

ZEHR, Howard. Justiça restaurativa. Tradução de Tônia Van Acker. São Paulo: Palas Athena, 2012. 